H. ELTRINGHAM, M.A., D.Sc., F.R.S.

On some peculiarities of the abdominal structure in certain male Trichoptera.

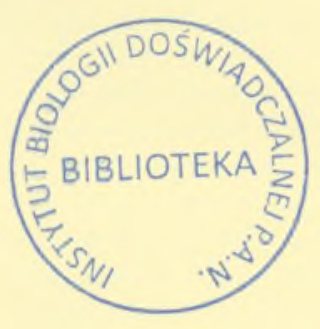

From the Transactions of the Entomological Society of London, Vol. LXXIX, Degember 3i, i93 I 
rcin.org.pl 


\title{
ON SOME PECULIARITIES OF THE ABDOMINAL STRUCTURE IN CERTAIN MALE TRICHOPTERA
}

\author{
By H. Eltringha.i, M.A., D.Sc., F.R.S.
}

[Read 3rd June, 1931.]

\section{With Plates XL and Xli and Three Text-figures.}

Some years ago my friend Mr. Martin E. Mosely made the remarkable discovery of the male scent-organs in the genus Hydroptila and very kindly supplied me with material for the paper published in Trans. Ent. Soc. Lond., 1919, in which I described and figured the histology of these minute and complicated structures.

Further research on other genera and species of the smaller Trichoptera has been hampered by lack of fresh material. Large supplies of formol preserved material have been available, but hitherto our methods have not been successfully applicable to any material preserved in formol owing to the hardening action of this reagent when applied to chitin. Quite recently a preparation known as Diaphanol has been placed on the market, and I have found that, provided the chitin is not very dense, it can be sufficiently modified, by treatment with this fluid, to enable good sections to be obtained. As a result I am now able to describe certain very curious structures in species of other genera of the smaller Trichoptera. As in Hydroptila these features were originally discovered by Mr. Mosely, and I am once more indebted to him for the opportunity of investigating them.

The species so far examined belong to the genera Diplectrona (Hydropsychidae) and Agapetus (Rhyacophilidae). Cleared examples of Diplectrona felix, McL., mounted whole, showed that in the male abdomen there were four comparatively large bodies, apparently in the nature of vesicles, the walls of which are chitinous and beautifully reticulated. They lie ventrolaterally in the fifth and sixth abdominal segments. It seemed probable that they might be of a glandular nature, but the original examples in which they were observed had been treated with caustic, so that any glandular material, if originally present, would not have been preserved. Fresh material was secured and sections prepared. These, however, did not show any glandular structure whatever. Indeed the vesicles proved to be quite empty and provided with large canals or slits opening directly to the atmosphere. Such a condition indicated a tracheal origin, but at first no tracheal connection could with certainty be traced. Further series of sections, however, ultimately placed the tracheal interpretation beyond any doubt, and it is evident that for some purpose difficult to define, these insects have, in the male only, two large tracheal vesicles on each side. Plate XL, fig. 1, is a microphotograph of a section of part of the male abdomen of Diplectrona felix. The section, as also those shown in figs. 2 and 3 , was made in a plane parallel to that of the expanded wings. The four tracheal vesicles, of which one is marked $T V$, in fig. 1, are distinctly seen with their reticulated supporting membrane and their direct openings to the exterior, one of which is marked $P$ in fig. 2. $A G$ is one of the large accessory glands of the genital apparatus which I shall TRANS. ENT. SOC. LOND. 79. PART III. (DEC. 1931.) 
describe later. In Plate XL, fig. $2, T$ is a trachea connecting directly with the adjacent vesicle. In fig. 3 the section has coincided with the surface membrane of one of the vesicles $T V$, and shows very clearly the reticulated structure, the function of which is doubtless to maintain the shape and expansion of the vesicle against the external blood pressure. These structures are not the same in number in all species, and there may either be four, as in D. felix, or two large vesicles with rudiments of the remaining pair, or in Diplectronella, originally separated as a species on account of the absence of fork 1 in the posterior wing, none at all.

Turning now to the genus Agapetus (Rhyacophilidae), the material so far examined has included $A$. fuscipes, Curtis, cyrnensis, Mosely, and nimbulus, McL. These have two tracheal vesicles only, and they are of a somewhat different structure. The reticulation is absent and the necessary stiffening is provided by a thickening of the membrane. Plate XL, fig. 4, shows, at $T V$, the upper part of a vesicle not yet open to the exterior. $T S$ is a testis, and between this and the corresponding testis of the other side can be seen a part of the intestine with the junction of the malpighian tubes. $A G, A G$, are portions of the accessory glands of the genital apparatus. In fig. 5 the form of the vesicle has begun to change, and a secondary vesicle, $S V$, appears. $T S$ is again the testis. In fig. 6 the secondary vesicle has disappeared and the main structure $T V$ has expanded and developed an internal septum. The shape and plications of these lateral vesicles in Agapetus fuscipes is so complicated that no mere verbal description would convey an adequate idea of their form. I have therefore made reflector drawings of a series of $48 \mathrm{con}$ secutive sections taken in the plane of the expanded wings, and these are reproduced on Plate XLI. In fig. 1 a part of the trachea only is seen, but in 2 the section has touched the upper part of the vesicle where the trachea enters it. From 3 to 7 inclusive the dome-like structure expands and at 8 the opening to the exterior first appears. From 5 to 8 there is a small diverticulum at the anterior end. At 9 the large black area is the upper surface of a secondary vesicle which shows a gradual expansion up to section 14, where it develops an independent opening to the exterior. This opening persists as far as 18, but both it and the secondary vesicle itself disappear at 19. This secondary structure has no tracheal connection and seems to be merely a small diverticulum of the cuticle. It contains only air, and its function, if any, is quite obscure. From 16 to 22 the main vesicle develops internal projections which die out suddenly in 23 . In 25 to 27 the anterior end develops small plications, and at 29 the section strikes the beginning of a deep fold, the two sides of which ultimately coalesce to form a septum, which persists as far as 44 . The main opening to the exterior continues from 8 to 37 , showing that it has the form of a long, more or less vertical slot. From 38 to 48 the vesicle is closed to the exterior and merely forms a downwardly projecting concavity.

These peculiar structures are similar in the other species so far examined, but organs of a somewhat different type occur in species of which I hope soon to secure examples.

The meaning of these tracheal expansions, found as they are only in the male, is extremely difficult to imagine. So far as Mr. Mosely has been able to observe, the pairing habits, at any rate of Agapetus fuscipes, present no peculiar features. If the male pursued the female on or beneath the surface of the water, one might suggest some hydrostatic function, but skimming or diving do not appear to be involved. We know that in Mayflies the whole digestive tract is modified into an aerostatic apparatus, but the vesicles in 
Diplectrona and Agapetus would not appear to afford a sufficient displacement volume to be of importance in this respect. There would seem to be a great opportunity for careful field observations, though the small size of the insects entails considerable difficulties.

\section{The Lateral Glands in Agapetes.}

The majority of my sections of Agapetus show the existence of an exceedingly small but very complicated structure lying in close proximity to the tracheal vesicles and just anterior to them. It appeared to me to be a glandular organ but of such unusual form that I invoked the aid of my friend Dr. A. D. Imms, F.R.S., to whom I am greatly indebted for valuable advice and suggestions. In the series of sections on Plate XLI, I have indicated more or less diagrammatically the position of this gland. The first trace of it appears in

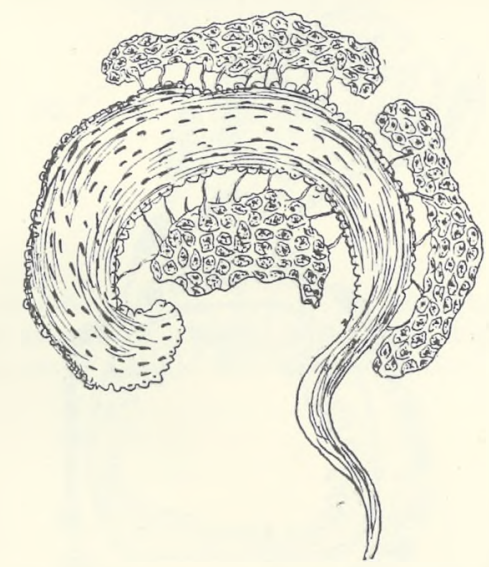

A. Diagrammatic representation of the lateral gland and duct of Agapetus.

section 23 , and at 25 its duct is connected with the external cuticle, though the actual opening to the exterior cannot in this series be observed. The opening is in fact so small that one is liable to miss it even in sections $4 \mu$ thick. The gland disappears again at section 31. The apparatus consists of a convoluted duct, rather thick at its blind or proximal end but tapering distally towards its opening to the exterior. Lying massed round this duct is the gland tissue, consisting of heavily nucleated cells. These secretory cells are not in direct contact with the duct, but communicate therewith through a number of exceedingly fine ducteoles. Text-figure A is a purely diagrammatic representation of the organ, three masses of the glandular tissue being shown grouped round the curved and tapering duct. Text-figure B is a reflector drawing of a section from an example of Agapetus cyrnensis under the $1 / 2$ in. immersion objective, passing transversely through the duct, and including a few cells of the gland with their ducteoles. The duct appears to be double in this section, having an outer layer of heavily nucleated cells and an inner stratum of fibrous material. This appearance is not common to all sections of the duct, and seems to occur most frequently near the distal end. It strongly suggests an invagination and a possible eversible property of the duct, though no example has yet been found with the part actually protruding. 
The cells of the gland tissue do not present any very complicated structure as found for instance in some Lepidopterous glands. The ducteoles are sometimes swollen and granular, suggesting the passage of a secretion. At their normal size they are about $.0003 \mathrm{~mm}$. in diameter. Plate XL, fig. 7, shows a microphotograph of a section of part of the abdomen of Agapetus cyrnensis with portions of the gland and duct, though details cannot be seen at this magnification. Sections of the duct are marked $D, D$, and $G$ is a small part of the gland. $O$ points to three oenocytes which are nearly always present in association with the structure. Of the precise function of oenocytes we know very little, some authors having regarded them as excretory, and others as fulfilling functions analogous to those of the ductless glands in vertebrates. So far I have found this gland only in species of Agapetus and cannot discover any similar structure in Diplectrona. Occurring only in the males we must assume that it has some sexual function. Though it lies close to the

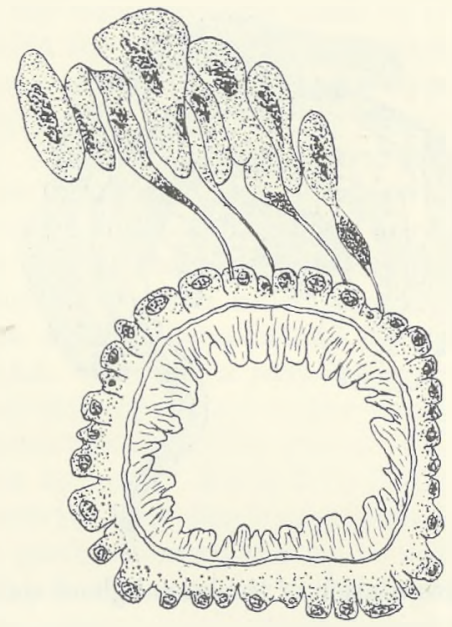

B. Reflector drawing of cross-section of duct of lateral gland in Agapetus cyrnensis, with a few cells of the gland and their ducteoles.

tracheal vesicles already described, it does not communicate with them, and it is difficult to suppose any kind of co-operation between the two organs. Its form is quite unusual, the nearest structure bearing even a faint resemblance being, as Dr. Imms has suggested, the pygidial glands of some Coleoptera.

\section{The Internal Male Reproductive Organs.}

The internal organs of the smaller Trichoptera have apparently been but little studied. The dissection and sectioning of numerous examples has afforded an opportunity of examining them, and it seems desirable here briefly to record their arrangement. The most prominent feature is the comparatively enormous accessory glands. Text-figure $\mathrm{C}$ shows the general arrangement. The two testes, one of which is marked $T$, are quite separate, and their ducts, $T D$, open at $J$ into those of the accessory glands $A G, A G$, shortly before these join the ejaculatory duct $E D$. The accessory glands occupy a large part of the body cavity. It is difficult to account for the presence of such large organs, unless pairing takes place several times by the same 
male. $A$ is the aedeagus. Both the testis and accessory ducts are convoluted. In the figure, $G$ is the intestine, $M$ the malpighian tubes, of which there are, as usual in the Trichoptera, six branches, and $H G$ is the hind-gut.

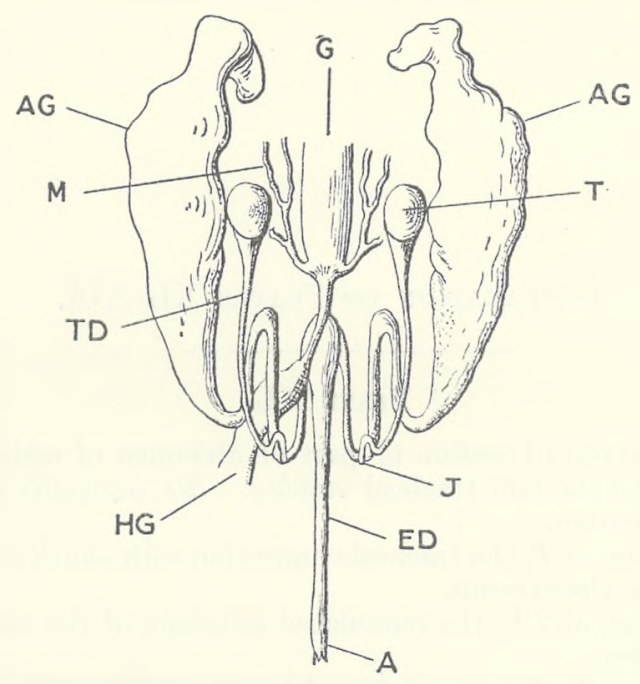

C. Internal organs of male Agapetus fuscipes. $G$, gut. $M$, malpighian tubes. $H G$, hind-gut. $A G, A G$, accessory glands. $T$, testis. $T D$, testis duct. $J$, junction of testis duct with that of accessory gland. $E D$, ejaculatory duct. $A$, aedeagus.

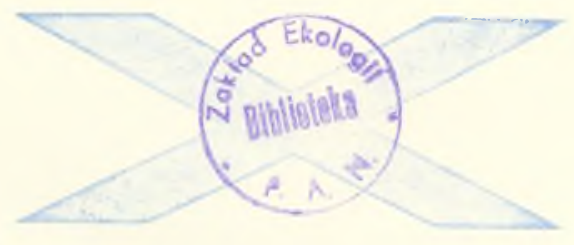




\section{Explanation of Plates XL-XLI.}

\section{Plate XL.}

Fig. 1. Microphotograph of section of part of abdomen of male Diplectrona felix. $T V$, one of the four tracheal vesicles. $A G$, accessory gland of the reproductive system.

2. Ditto showing, at $T$, the tracheal connection with one of the vesicles. $P$, the passage to the exterior.

3. Ditto showing, at $T V$, the reticulated structure of the membrane of one of the vesicles.

4. Microphotograph of part of the abdomen of the male Agapetus fuscipes. $T S$, testis. $T V$, tracheal vesicles. $A G, A G$, accessory glands.

5. Ditto. TS, testis. $S V$, secondary vesicle.

6. Ditto. $T V$, tracheal vesicle.

7. Section of part of the male abdomen of Agapetus cyrnensis, showing part of lateral gland and duct. $D, D$, parts of duct. $G$, part of gland. $O$, oenocytes.

\section{Plate XLI.}

A continuous series of 48 sections of the tracheal vesicle of a male Agapetus fuscipes. For description see text. 


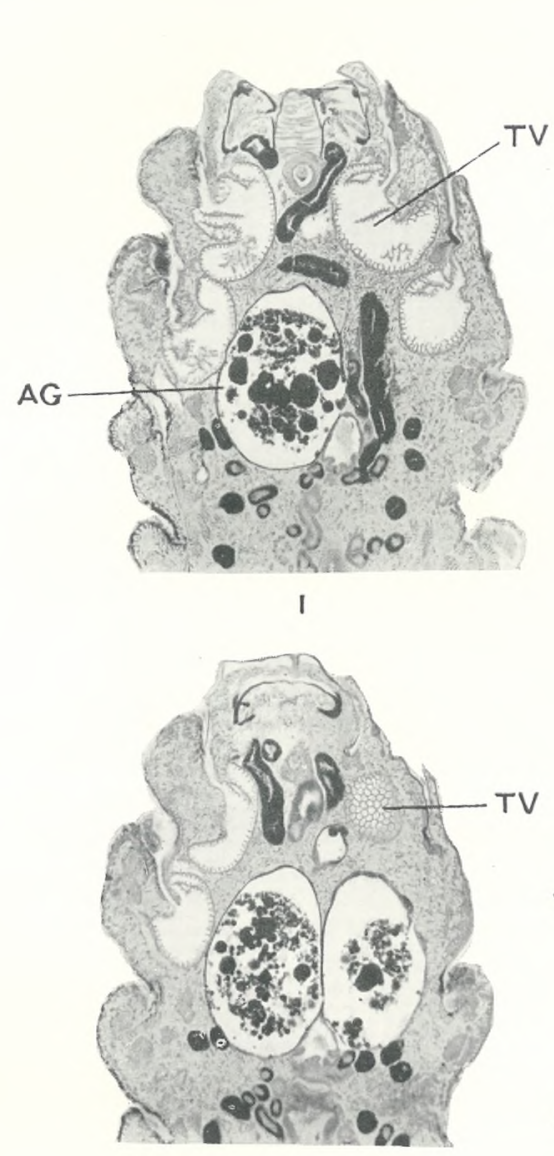

3
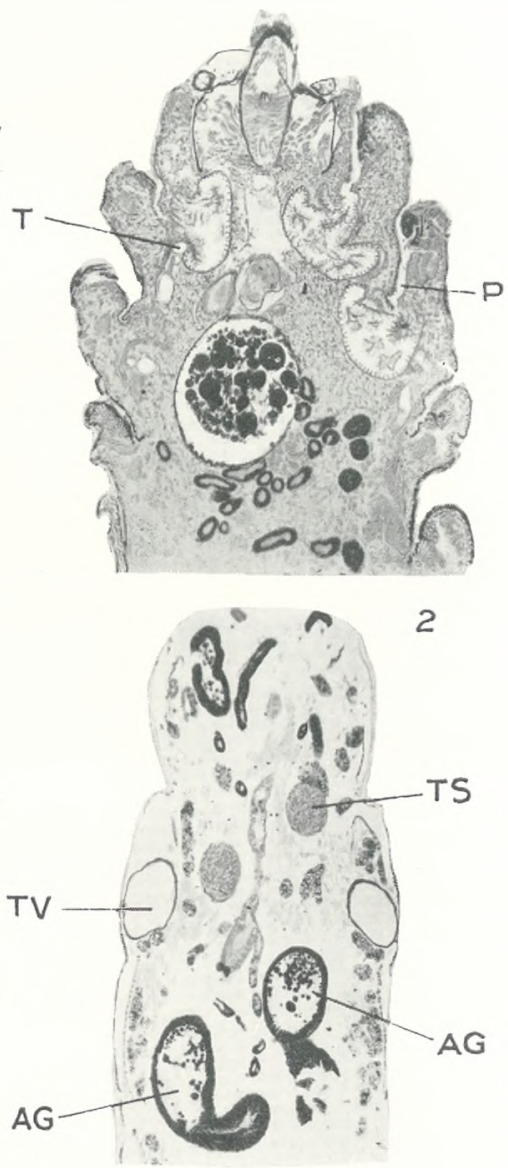

4

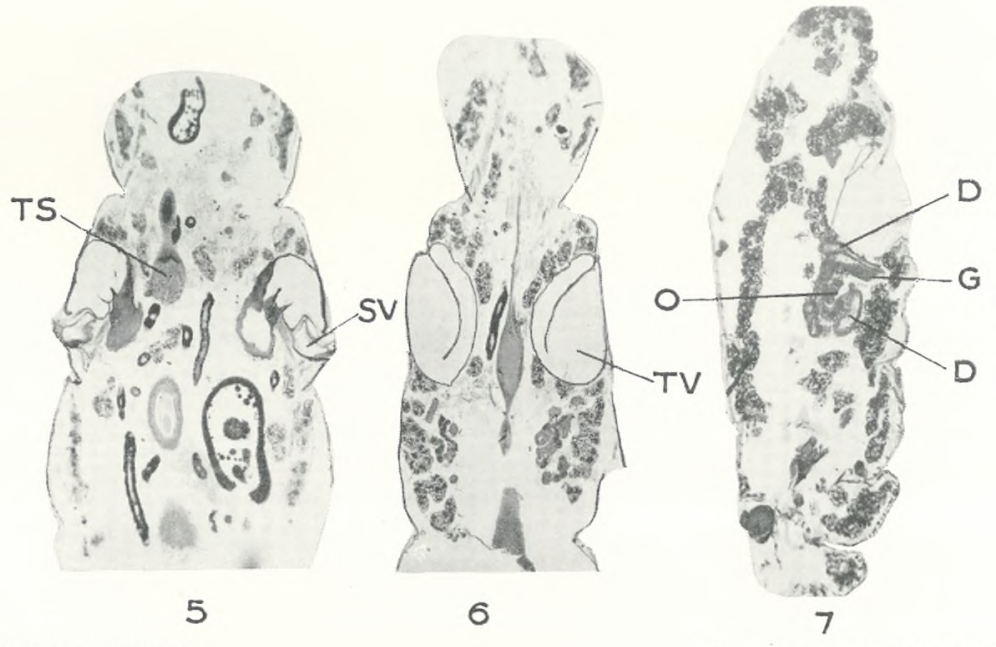

H. Eltringham microphoto.

Art Reproduction Co., Ltd,

Tracheal Vesicles in Trichoptera.

rcin.org.pl 


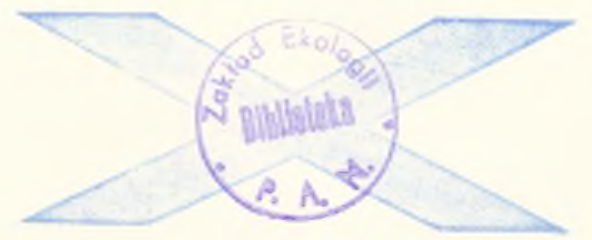

rcin.org.pl 

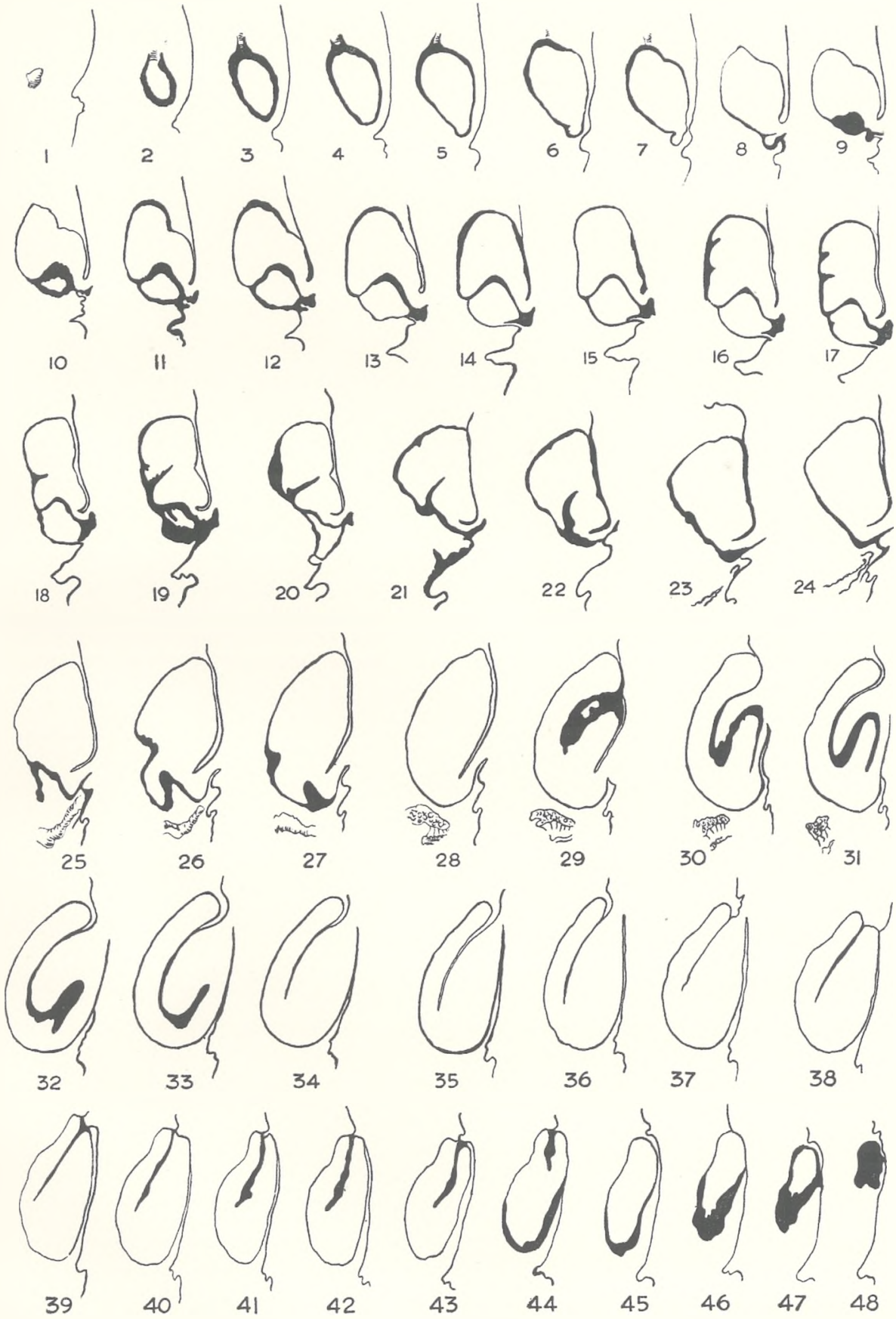

H. Eltringham del.

Art Reproduction Co., Ltd.

Series of Continuous Sections of a Tracheal Vesicle of Agapetus fuscipes. 


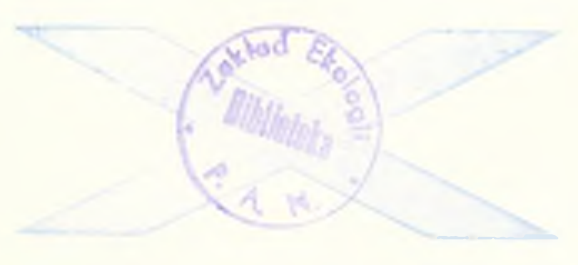

rcin.org.pl 
rcin.org.pl 
rcin.org.pl 